\title{
INFORMATION FOR AUTHORS SUBMISSION PROCESS
}

\section{Submission Process}

The manuscript submission process is broken into a series of 5 screens that gather detailed information about your manuscript and allow you to upload the pertinent files.

The sequence of screens are as follows:

1. A long form asking for author information, title, abstract, and file quantities.

2. A screen asking for the actual file locations on your computer (via an open file dialog). After completing this screen, your files will be uploaded to our server.

3. A screen requesting the order files should appear in the systemgenerated merged PDF.

4. A completion screen that will provide you with a specific manuscript number for your manuscript.

5. An approval screen that will allow you to verify that your manuscript was uploaded and converted correctly. You are allowed to replace and delete files, as well as withdraw the manuscript, on this page.

Before submitting a manuscript, please gather the following information:

- All Authors First Names, Middle Names/Initials, Last Names

- Author affiliations/Institutions

- Departments

- Phone and Fax Numbers

- Street Addresses

- E-mail Addresses

- Title and Running Title (you may copy and paste these from your manuscript) YOUR TITLE MUST BE UNDER 80 CHARACTERS (including spaces)

- Structured Abstract (unless a Review Article, then Unstructured)

\section{File Formats}

- Manuscript files in Word, WordPerfect, or Text formats

- Figures/Images in TIF, EPS, PDF, or JPG formats (must follow high resolution formats below)

- Tables in XLS or DOC formats

- Figure/File mode/Ideal resolution/Minimum resolution

- Line Bitmap 1200 dpi(ideal) 600 dpi(min)

- Color photo CMYK 300 dpi(ideal) 200 dpi(min)

- Black and White photos Grayscale 300 dpi(ideal) 200 dpi(min)

- Line/halftone combination Grayscale 600 dpi(ideal) 200 dpi(min)

Uniform Requirements for Manuscripts Submitted to Biomedical Journals: Writing and Editing for Biomedical Publication International Committee of Medical Journal Editors

For detailed instructions regarding style and layout refer to "Uniform requirements for manuscripts submitted to biomedical journals". Copies of this document may be obtained on the website http://www.icmje.org. Articles should be submitted under conventional headings of introduction, methods and materials, results, discussion, but other headings will be considered if more suitable. For Uniform Requirements for Sample References go to http://www.nlm.nih.gov/bsd/uniform_requirements.html.

After the manuscript is submitted, you will be asked to select the order you would like the files to be displayed in a merged PDF file that the system will create for you. Next, you will be directed to a page that will allow you to review your converted manuscript. If the conversion is not correct, you can replace or delete your manuscript files as necessary. You may also add additional files at this time. After you have reviewed the converted files, you will need to click on "Approve Converted Files." This link will have a red arrow next to it. Throughout the system, red arrows reflect pending action items that you should address.

\section{Cover Letter}

A cover letter is required and must state that the manuscript: has not been published elsewhere, except in abstract form, and is not under simultaneous consideration by another journal. Once a decision is made by the Editor on your manuscript, the Journal office will send you an Author Release form and a Conflict of Interest form if your manuscript has been accepted for revision.

\section{Abstracts}

Original Articles should be accompanied by a Structured abstract of 250 words or less on a separate page, in either English or French. The Journal will provide translation to the other language if required. Abstracts should consist of four paragraphs headed: Background (or objective), Methods, Results and Conclusions. Review articles should be accompanied by an Unstructured abstract of 150 words or less. Brief Communications (Case Reports) require no Abstract.

\section{Acknowledgements}

Acknowledgements, including recognition of financial support, should be typed on a separate page at the end of the text. The SI system (système international d'unités) should be used in reporting all laboratory data, even if originally reported in another system. Temperatures are reported in degrees celsius. English language text may use either British or American spelling, but should be consistent throughout.

\section{References}

References should be numbered in the order of their citation in the text. Those cited only in tables and legends for illustrations are numbered according to the sequence established by the first identification in the text of a particular table or illustration.

Titles of journals should be abbreviated according to the style used in Index Medicus.

References should list the names of up to three authors; if there are more, cite the first THREE, then et al.

Provide the full title, year of publication, volume number and inclusive pagination for journal articles. Unpublished articles should be cited as [in press]. Do not reference unpublished or "submitted" papers; these can be mentioned in the body of the text.

Avoid "personal communications" and, if necessary, include them in the body of the text, not among the references. Reference citations should not include unpublished presentations or other nonaccessible material. Books or chapter references should also include the place of publication and the name of the publisher.

For Reference Guidelines www.nlm.nih.gov/bsd/uniform_ requirements.html.

\section{Examples of correct forms of reference:}

\section{Journals}

1. Rose ME, Huerbin MB, Melick J, et al. Regulation of interstitial excitatory amino acid concentrations after cortical contusion injury. Brain Res. 2002; 935(1-2):40-6.

\section{Chapter in a book}

1. Meltzer PS, Kallioniemi A, Trent JM. Chromosome alterations in human solid tumors. In: Vogelstein B, Kinzler KW, editors. The genetic basis of human cancer. New York: McGraw-Hill; 2002. p. 93-113.

\section{Tables}

Type tables double-spaced on pages separate from the text. Provide a table number and title for each. Particular care should be taken in the preparation of tables to ensure that the data are presented clearly and concisely. Each column should have a short or abbreviated heading. Place explanatory matter in footnotes, not in the heading. Do not submit tables as photographs. 


\section{INFORMATION FOR AUTHORS SUBMISSION PROCESS (continued)}

\section{Review Articles}

Review articles on selected topics are also published. They are usually invited, but unsolicited reviews will be considered. Review articles should be accompanied by an Unstructured abstract of 150 words or less.

\section{Brief Communications}

Brief Communciations are published on various topics and should be limited to approximately $9-12$ double-spaced manuscript pages (3 - 4 Journal pages) and may include illustrations and tables. Brief Communciations do not require an abstract.

\section{Editor Correspondence}

Correspondence to the Editor concerning matters arising in recent articles are welcome. Correspondence should be limited to two double-spaced pages and may include one illustration and a maximum of four references.

\section{Critically Appraised Topics (CATs)}

Current research in clinical neurosciences. Each CAT will appraise one or two recent research articles dealing with a particular topic. Meta-analyses and systematic reviews will also be considered if pertaining to evidence-based neurological/neurosurgical practice. A complete CAT is a one or 2 page summary that includes all of the following:

A brief title that summarizes the conclusion reached about the article.

Clinical Bottom Lines consisting of short statements summarizing the key "take-home" points. The clinical problem which cues the reader to the nature of the case. The clinical problem comes from real life dilemmas that are faced by clinicians. The clinical question includes the patient, intervention, comparator, and outcome.

The search strategy - including search terms, search engines used, and the reasons why the article chosen is the best evidence for the clinical question.

The evidence is described briefly including the type of study, patient population, and outcomes reported for the article reviewed.

The data is usually presented in tabular form and highlights the clinically significant data such as number needed to treat, specificity, hazard ratios, etc.

Comments are added regarding the quality of the study and any concerns which were identified by the critical appraisal process.

The reference, the appraiser, the date appraised, and the date expired.

Lastly, it will include a clinical comment from an "expert" on the particular topic.

\section{Neuroimaging Highlights}

Neuroimaging Highlights are selected by the Editor-in-Chief and Neuroimaging Highlight Editors on the basis of two factors. The first is high quality "state of the art" imaging of a novel and uncommon (or common with an uncommon twist) neurological or neurosurgical disorder. The second factor is the clinical novelty of the case.

Neuroimaging Highlights require a figure of several panels that clearly outlines all features of the relevant imaging. For example, for MR images this may require different cuts and sequences, etc. Combining more than one imaging modality strengthens the report. The report may also benefit from a single additional panel in a figure if it is directly relevant, e.g. a pathological image or patient image. The text should include a very brief discussion of the case history confined to the relevant history, pertinent abnormal findings, and clinical course with outcome. An additional one to two paragraphs should briefly describe the
Neuroimaging panels present, and very briefly review relevant aspects of the literature. Overall, the Neuroimaging Highlights should be 500 words or less, with no more than 10 references.

Images should be of the highest quality, submitted electronically as a tif file at a minimum of $300 \mathrm{dpi}$ and at a size large enough for the printed journal (i.e. not less than 3 1/2" wide).

Suitability for publication is judged by a Neuroimaging Highlight Editor, the Editor-in-Chief and up to one additional external referee.

\section{Permissions and Releases}

Any non-original material (quotations, tables, figures) must be accompanied by written permission from the author and the copyright owner to reproduce the material in the Journal. Photographs of recognizable persons must be accompanied by a signed release from the legal guardian or patient authorizing publication.

\section{Conflict of Interest}

Authors who have non-scientific or non-academic gain, whether it be financial or other, from publishing their article are responsible for declaring it to the Editor. Any financial interest, research grant, material support, or consulting fee associated with the contents of the manuscript must be declared to the Editor. These guidelines apply to each author and their immediate families. Conflicts of interest are not necessarily wrong, nor do they necessarily change the scientific validity of research or opinion, but the Journal and readers should be aware of the conflict. If the Editor considers the conflict to compromise the validity of the paper, it will not be accepted for publication.

Authors, editorial staff and reviewers are asked to declare any relationship that would be considered as a conflict of interest whether or not they believe that a conflict actually exists. Information that the Journal receives about conflict or potential conflict will be kept confidential unless the Editor or Associate Editor considers it to be important to readers. Such conflicts will be published in the author credits or as a footnote to the paper, with knowledge of the authors.

\section{Getting Help}

If you need additional help, you can click on the help signs spread throughout the system. A help dialog will pop up with contextsensitive help.

\section{Manuscript Status}

After you approve your manuscript, you are finished with the submission process. You can access the status of your manuscript at any time via:

\section{Logging into the system with your password}

Clicking on the link represented by your manuscript tracking number and abbreviated title

Clicking on the "Check Status" link at the bottom of the displayed page

This procedure will display detailed tracking information about where your manuscript is in the submission/peer-review process.

\section{Starting}

The manuscript submission process starts by pressing the "Submit Manuscript" link on your "Home" page. Please make sure you have gathered all the required manuscript information listed above BEFORE starting the submission process. 


\section{PAIN FELLOWSHIP AT THE UNIVERSITY OF WESTERN ONTARIO}

The University of Western Ontario Pain Program is offering a 1-year Clinical Fellowship in Neuropathic Pain starting July 1, 2010. Salary and benefits will be competitive at the fellowship level.

Fellows will participate in the evaluation and treatment of patients with a broad range of neuropathic pain syndromes including:

- Painful diabetic neuropathy

- Post-herpetic neuralgia

- Failed back syndrome

- Complex regional pain syndrome

- Cancer neuropathic pain

Fellows will learn or become familiar with different treatment modalities including:

- Evidence-based pharmacologic management

- Local anesthetic infusions

- Spinal cord stimulation

- Intrathecal therapy

- Motor cortex stimulation

Fellows are expected to be involved in clinical research projects. However there is no requirement to take call during the fellowship program. Candidates must be eligible for an educational licence in Ontario. Interested candidates should send three letters of reference along with their cover letter outlining why they wish to do a neuropathic pain fellowship.

\section{Applications with CV should be sent to:}

Dwight Moulin, M.D., FRCP(C)

Earl Russell Chair UWO Pain Program

Victoria Hospital, 800 Commissioners Rd E

London, Ontario N6A 4G5

Tel: $519-685-8661$

Fax: $519-685-8636$

E-mail: dwight.moulin@Ihsc.on.ca

Applicants should have fluent written and oral communication skills in English. All qualified applicants are encouraged to apply. The University of Western Ontario is committed to employment equity and welcomes applications from all qualified women and men, including visible minorities, aboriginal people and persons with disabilities.

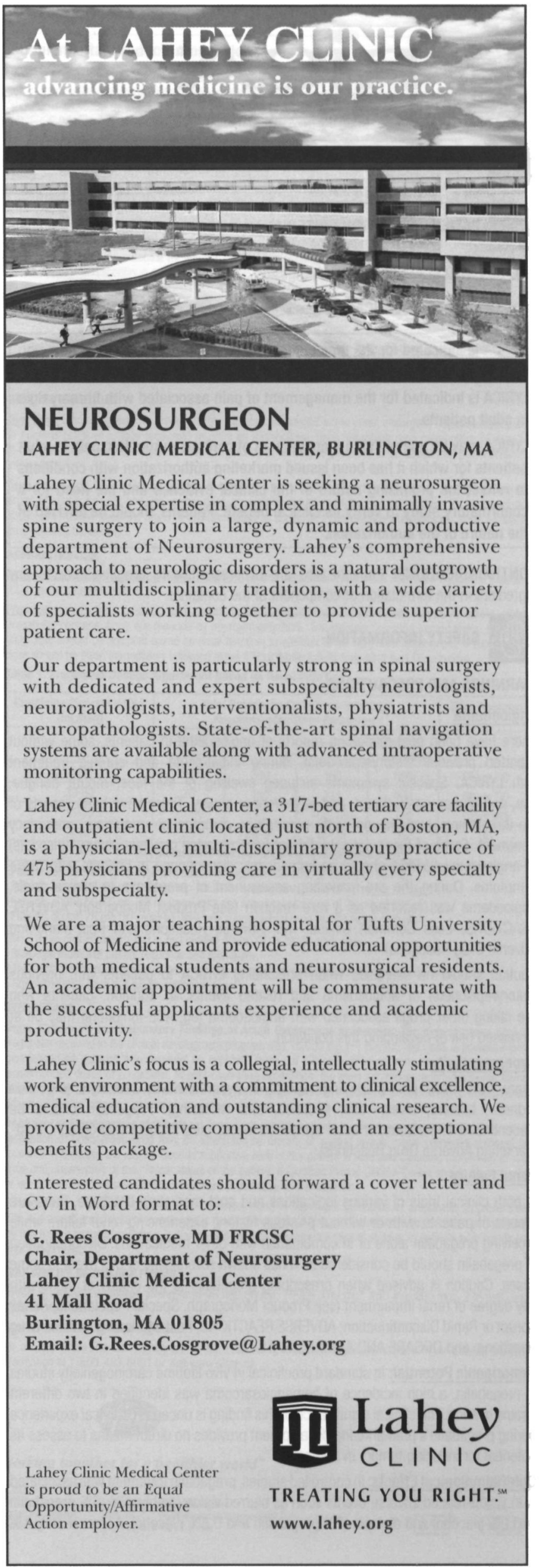




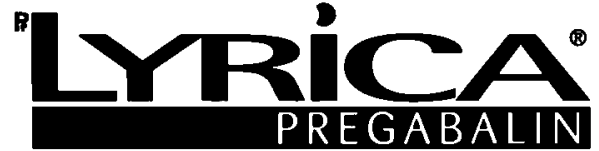

PRESCRIBING SUMMARY

\section{PATIENT SELECTION CRITERIA}

THERAPEUTIC CLASSIFICATION: Analgesic Agent

\section{INDICATIONS AND CLINICAL USE}

LYRICA is indicated for the management of neuropathic pain associated with diabetic peripheral neuropathy and postherpetic neuralgia in adult patients.

LYRICA is indicated for the management of pain associated with fibromyalgia in adult patients.

LYRICA may be useful in the management of central neuropathic pain in adult patients for which it has been issued marketing authorization with conditions to reflect the promising nature of the clinical evidence and the need for a confirmatory study to verify its clinical benefit. Patients should be advised of the nature of the authorization.

CONTRAINDICATIONS: Patients who are hypersensitive to pregabalin or to any ingredient in the formulation or component of the container.

\section{SAFETY INFORMATION}

\section{WARNINGS AND PRECAUTIONS}

\section{Angioedema}

There have been post-marketing reports of angioedema in patients, some without reported previous history/episode(s), during initial/acute and chronic treatment with LYRICA. Specific symptoms included swelling of the face, mouth (tongue, lips, and gums), neck, throat, and larynx/upper airway. There have been reports of life-threatening angioedema with respiratory compromise requiring emergency treatment. Some of these patients did not have reported previous history/episode(s) of angioedema. LYRICA should be immediately discontinued in patients with these symptoms. During the pre-marketing assessment of pregabalin in clinical trials, angioedema was reported as a rare reaction (see Product Monograph, ADVERSE REACTIONS, Less Common Clinical Trial Adverse Reactions and Post-Marketing Adverse Drug Reactions)

Caution should be exercised when prescribing LYRICA to patients with previous history/episode(s) of angioedema and related events. In addition, patients who are taking other drugs associated with angioedema (eg, ACE-inhibitors) may be at increased risk of developing this condition.

\section{Hypersensitivity}

There have been post-marketing reports of hypersensitivity reactions (e.g. skin redness, blisters, hives, rash, dyspnea, and wheezing). Pregabalin should be discontinued immediately if such symptoms occur (see Product Monograph, PostMarketing Adverse Drug Reactions)

\section{Renal Failure}

In both clinical trials of various indications and post-marketing database, there are reports of patients, with or without previous history, experiencing renal failure while receiving pregabalin alone or in combination with other medications. Discontinuation of pregabalin should be considered as it has shown reversibility of this event in some cases. Caution is advised when prescribing pregabalin to the elderly or those with any degree of renal impairment (see Product Monograph, Special Populations, Renal; Abrupt or Rapid Discontinuation; ADVERSE REACTIONS, Post-Marketing Adverse Drug Reactions; and DOSAGE AND ADMINISTRATION).

Tumorigenic Potential: In standard preclinical in vivo lifetime carcinogenicity studies of pregabalin, a high incidence of hemangiosarcoma was identified in two different strains of mice. The clinical significance of this finding is uncertain. Clinical experience during pregabalin's premarketing development provides no direct means to assess its potential for inducing tumors in humans.

Ophthaimological Effects: In controlled studies, pregabalin treatment was associated with vision-related adverse events such as blurred vision (amblyopia) (6\% pregabalin and $2 \%$ placebo) and diplopia ( $2 \%$ pregabalin and $0.5 \%$ placebo). Approximately $1 \%$ of pregabalin-treated patients discontinued treatment due to vision-related adverse events (primarily blurred vision). Of the patients who did not withdraw, the biurred vision resolved with continued dosing in approximately half of the cases (see Product Monograph, Post-Marketing Adverse Drug Reactions).

Patients should be informed that if changes in vision occur, they should notify their physician.

Peripheral Edema: LYRICA may cause peripheral edema. In controlled clinical trials, pregabalin treatment caused peripheral edema in $6 \%$ of patients compared with $2 \%$ of patients in the placebo group. In these studies, $0.5 \%$ of pregabalin patients and $0.2 \%$ of placebo patients withdrew due to peripheral edema (see Product Monograph, ADVERSE REACTIONS, Peripheral Edema).

In controlled clinical trials of up to 13 weeks in duration of patients without clinically significant heart or peripheral vascular disease, there was no apparent association between peripheral edema and cardiovascular complications such as hypertension or congestive heart failure. In the same trials, peripheral edema was not associated with laboratory changes suggestive of deterioration in renal or hepatic function.

Higher frequencies of weight gain and peripheral edema were observed in patients taking both LYRICA and a thiazolidinedione antidiabetic agent compared to patients taking either drug alone. As the thiazolidinedione class of antidiabetic drugs can cause weight gain and/or fluid retention, possibly exacerbating or leading to heart failure, care should be taken when co-administering LYRICA and these agents.

Congestive Heart Failure: In controlled clinical studies, events of congestive heart failure were reported at an infrequent rate between $0.1 \%$ and $1 \%$; see Product Monograph, ADVERSE REACTIONS, Less Common Clinical Trial Adverse Reactions).

There have been post-marketing reports of congestive heart failure in some patients receiving pregabalin (see Product Monograph, ADVERSE REACTIONS, Post-marketing Adverse Drug Reactions). Although this adverse reaction has mostly been observed in elderly cardiovascular-compromised patients during pregabalin treatment for a neuropathic pain indication, some cases have occurred in patients without reported edema or previous history of cardiovascular disease. Pregabalin should be used with caution in these patients. Discontinuation of pregabalin may resolve the reaction.

Weight Gain: LYRICA may cause weight gain. In pregabalin-controlled clinical trials with durations of up to 14 weeks, a gain of $7 \%$ or more over baseline weight was observed in $8 \%$ of pregabalin-treated patients and $2 \%$ of placebo-treated patients. Few patients treated with pregabalin $(0.4 \%)$ withdrew from controlled trials due to weight gain (see Product Monograph, ADVERSE REACTIONS, Weight Gain). Pregabalinassociated weight gain was related to dose and duration of exposure.

Pregabalin-associated weight gain did not appear to be associated with baseline BMI, gender, or age. Weight gain was not limited to patients with edema and was not necessarily due to edema-related events (see Product Monograph, WARNINGS AND PRECAUTIONS, Peripheral Edema).

Although weight gain was not associated with clinically important changes in blood pressure in short-term controlled studies, the long-term cardiovascular effects of pregabalin-associated weight gain are unknown.

While the effects of pregabalin-associated weight gain on glycemic control have not been systematically assessed, in controlled and longer-term open-label clinical trials with diabetic patients, pregabalin treatment did not appear to be associated with loss of glycemic control (as measured by $\mathrm{HbA}_{1 \mathrm{c}}$ ).

Dizziness and Somnolence: LYRICA may cause dizziness and somnolence. In controlled studies, pregabalin caused dizziness in $31 \%$ of patients compared to $9 \%$ in placebo. Somnolence was experienced by $22 \%$ and $7 \%$ of the patients treated with pregabalin and placebo, respectively. These events begin shortly after the initiation of therapy and generally occur more frequently at higher doses. in these studies dizziness and somnolence led to withdrawal of $5 \%$ (placebo: $0.6 \%$ ) and $3 \%$ (placebo: $0.3 \%)$ of the pregabalin-treated patients, respectively.

Abrupt or Rapid Discontinuation: Following abrupt or rapid discontinuation of pregabalin, some patients reported symptoms including insomnia, nausea, headache, and diarrhea. Pregabalin should be tapered gradually over a minimum of one week rather than discontinued abruptly (see Product Monograph, ADVERSE REACTIONS, Adverse Events Following Abrupt or Rapid Discontinuation).

\section{ADVERSE REACTIONS}

Because clinical trials are conducted under very specific conditions, the adverse reaction rates observed in clinical trials may not reflect the rates observed in practice and should not be compared to the rates in clinical trials of another drug. Adverse drug reaction information from clinical trials is useful for identifying drug related adverse events and for approximating rates

Clinical Trial Adverse Drug Reactions: Most Common Adverse Events in All Premarketing Controlled Clinical Studies of Neuropathic Pain: The most commonly 
observed adverse events ( $\geq 5 \%$ and twice the rate of that seen in placebo) in pregabalin-treated patients were: dizziness, somnolence, peripheral edema, and dry mouth. Adverse events were usually mild to moderate in intensity.

Adverse Events from a Controlled Clinical Study in Central Neuropathic Pain Associated with Spinal Cord Injury: The most commonly observed treatment-related adverse events ( $25 \%$ and twice the rate of that seen in placebo) in pregabalintreated patients were: somnolence, dizziness, asthenia, dry mouth, edema, myasthenia, constipation, thinking abnormal, amblyopia, and amnesia. Adverse events were usually mild to moderate in intensity.

Most Common Adverse Events in Controlled Clinical Studies in Fibromyalgia: The most commonly observed treatment-related adverse events ( $\geq 5 \%$ and twice the rate of that seen in placebo) in pregabalin-treated patients were: dizziness $(37.5 \%)$, somnolence (18.6\%), weight gain (10.6\%), dry mouth $(7.9 \%)$, blurred vision $(6.7 \%)$, peripheral edema $(6.1 \%)$, constipation $(5.8 \%)$, and disturbance in attention $(5.3 \%)$. Adverse events were usually mild to moderate in intensity.

To monitor drug safety, Health Canada collects information on serious and unexpected effects of drugs. If you suspect you have had a serious or unexpected reaction to this drug, you may notify Health Canada by telephone: 1-866-234-2345

\section{ADMINISTRATION}

\section{Dosing Considerations}

Patients with Impaired Renal Function: Pregabalin is primarily eliminated from the systemic circulation by renal excretion as unchanged drug. In some elderly patients and those with a medical history of significant renal insufficiency, daily dosages should be reduced accordingly (see Table in Supplemental Product Information).

\section{Adults:}

Neuropathic pain associated with diabetic peripheral neuropathy and postherpetic neuralgia: The recommended starting dose for LYRICA is $150 \mathrm{mg} /$ day, given in two or three divided doses (75 mg BID or $50 \mathrm{mg} T I D$ ), with or without food in patients with a creatinine clearance rate of at least $60 \mathrm{~mL} / \mathrm{min}$. Efficacy of LYRICA has been demonstrated within the first week. Based on individual patient response and tolerability, the dose may be increased to $150 \mathrm{mg}$ BID (300 mg/day) after one week.

For patients who experience significant and ongoing pain and can tolerate pregabalin $300 \mathrm{mg} /$ day well, maximum daily dose of $600 \mathrm{mg}$ ( $300 \mathrm{mg}$ twice a day, BID) can be used. However, in clinical trials, LYRICA $600 \mathrm{mg} /$ day did not provide additional significant efficacy and patients treated with this dose experienced markedly higher rates of adverse events and discontinued the trial more frequently (see Product Monograph, ADVERSE REACTIONS, Tables 1 and 5). Doses above $600 \mathrm{mg} /$ day have not been studied and are not recommended.

Central neuropathic pain: The recommended starting dose for LYRICA is $150 \mathrm{mg} /$ day, given in two divided doses (75 mg BID), with or without food in patients with a creatinine clearance rate of at least $60 \mathrm{~mL} / \mathrm{min}$. Efficacy of LYRICA has been demonstrated within the first week. Based on individual patient response and tolerability, the dose may be increased to $150 \mathrm{mg}$ BID ( $300 \mathrm{mg} /$ day) after one week. For patients who experience significant and ongoing pain and can tolerate pregabalin $300 \mathrm{mg} /$ day well, a maximum daily dose of $600 \mathrm{mg}$ ( $300 \mathrm{mg}$ twice a day, BID) may be considered. Doses above $600 \mathrm{mg} /$ day have not been studied and are not recommended.

Pain associated with fibromyalgia: The recommended dosage is 300 to $450 \mathrm{mg} /$ day, given in two divided doses. The recommended starting dose for LYRICA is $150 \mathrm{mg} /$ day, given in two divided doses (75 mg BID), with or without food in patients with a creatinine clearance rate of at least $60 \mathrm{~mL} / \mathrm{min}$. Based on individual response and tolerability, the dose may be increased to $150 \mathrm{mg} \mathrm{BID} \mathrm{(300} \mathrm{mg/day)} \mathrm{after} \mathrm{one}$ week. Patients who do not experience sufficient benefit with $300 \mathrm{mg} /$ day may be further increased to $225 \mathrm{mg}$ BID ( $450 \mathrm{mg} /$ day). In some patients, efficacy of LYRICA has been demonstrated within the first week.

For patients who experience significant and ongoing pain and can tolerate pregabalin $300 \mathrm{mg} /$ day well, maximum daily dose of $600 \mathrm{mg}$ ( $300 \mathrm{mg}$ twice a day, BID) can be used. However, in clinical trials of fibromyalgia, LYRICA $600 \mathrm{mg} /$ day did not provide additional significant efficacy and patients treated with this dose experienced significantly higher rates of adverse events and discontinued the trial more frequently (see Product Monograph, ADVERSE REACTIONS, Tables 7 and 10). In view of the dose-related adverse events, the decision to treat patients with doses above $450 \mathrm{mg} /$ day should be based on clinical judgment of the treating physician. Doses above $600 \mathrm{mg} /$ day have not been studied and are not recommended.

Administration: LYRICA is given orally with or without food.

\section{Supplemental Product Information}

Special Populations: Renal: There have been reports of patients, with or without previous history, experiencing renal failure while receiving pregabalin alone or in combination with other medications. Discontinuation of pregabalin showed reversibility of this event in some cases (see Product Monograph, WARNINGS AND PRECAUTIONS: ADVERSE REACTIONS, Post-Marketing Adverse Drug Reactions; and DOSAGE AND ADMINISTRATION). Because pregabalin is eliminated primarily by renal excretion, the dose of pregabalin should be adjusted as noted for elderly patients or those with renal impairment (see Product Monograph, ACTION AND CLINICAL PHARMACOLOGY and DOSAGE AND ADMINISTRATION)

Pregnant Women: There are no adequate and well-controlled studies in pregnant women. Pregabalin should be used during pregnancy only if the potential benefit justifies the potential risk to the fetus.

Labour and Delivery: The effects of pregabalin on labour and delivery in pregnant women are unknown.

Nursing Women: It is not known if pregabalin is excreted in human breast milk; however, it is present in the milk of rats. Because of the potential for adverse reactions in nursing infants from pregabalin, a decision should be made whether to discontinue nursing or to discontinue the drug, taking into account the importance of the drug to the mother.

Pediatrics ( $<18$ years of age): The safety and efficacy of pregabalin in pediatric patients $(<18$ years of age) have not been established.

WARNINGS AND PRECAUTIONS: See the Product Monograph for further information on the following tumorigenic potential, ophthalmological effects, peripheral edema, congestive heart failure, weight gain, dizziness and somnolence, sexual function/reproduction, and special populations.

\section{DRUG INTERACTIONS}

Overview: Since pregabalin is predominately excreted unchanged in the urine, undergoes negligible metabolism in humans ( $\leq 2 \%$ of a dose recovered in urine as metabolites), does not inhibit drug metabolism in vitro, and is not bound to plasma proteins, LYRICA (pregabalin) is unlikely to produce, or be subject to, pharmacokinetic interactions.

Drug Abuse and Dependence/Liability: Pregabalin is not known to be active at receptor sites associated with drugs of abuse. As with any CNS active drug. physicians should carefully evaluate patients for history of drug abuse and observe them for signs of LYRICA misuse or abuse (e.g., development of tolerance, dose escalation, drug-seeking behaviour).

\section{ADMINISTRATION}

Dosage Adjustment Based on Renal Function: Dosing adjustment should be based on creatinine clearance (Clcr), as indicated in Table 1.

Pregabalin is effectively removed from plasma by hemodialysis. Over a 4-hour hemodialysis treatment, plasma pregabalin concentrations are reduced by approximately $50 \%$. For patients receiving hemodialysis, pregabalin daily dose should be adjusted based on renal function. In addition to the daily dose adjustment, a supplementa dose should be given immediately following every 4-hour hemodialysis treatment (see Table below).

Table 1. Pregabalin Dosage Adjustment Based on Renal Function

\begin{tabular}{|c|c|c|c|c|c|}
\hline \multirow[t]{2}{*}{$\begin{array}{c}\text { Creatinine Clearance }\left(\mathrm{Cl}_{\mathrm{c}}\right) \\
(\mathrm{mL} / \mathrm{min})\end{array}$} & \multicolumn{4}{|c|}{$\begin{array}{l}\text { Total Pregabalin Daily Dose (mg/day) } \\
\text { Recommended Dose Escalation* }\end{array}$} & \multirow[t]{2}{*}{ Dose Regimen } \\
\hline & $\begin{array}{c}\text { Starting } \\
\text { dose }\end{array}$ & & & $\begin{array}{l}\text { Maximum } \\
\text { daily dose }\end{array}$ & \\
\hline$\geq 60$ & 150 & 300 & 450 & 600 & BID or TID \\
\hline $30-60$ & 75 & 150 & 225 & 300 & BID or TID \\
\hline $15-30$ & 25-50 & 75 & $100-150$ & 150 & $Q D$ or $B I D$ \\
\hline$<15$ & 25 & $25-50$ & $50-75$ & 75 & QD \\
\hline
\end{tabular}

Supplementary dosage following hemodialysis (mg) ${ }^{\mathrm{b}}$

Patients on the $25 \mathrm{mg}$ QD regimen: take one supplemental dose of $25 \mathrm{mg}$ or $50 \mathrm{mg}$

Patients on the $25-50 \mathrm{mg}$ QD regimen: take one supplemental dose of $50 \mathrm{mg}$ or $75 \mathrm{mg}$

Patients on the $50.75 \mathrm{mg}$ QD regimen: take one supplemental dose of $75 \mathrm{mg}$ or $100 \mathrm{mg}$

Patients on the $75 \mathrm{mg}$ QD regimen: take one supplemental dose of $100 \mathrm{mg}$ or $150 \mathrm{mg}$

TID = Three divided doses; BID = Two divided doses; $Q D=$ Single daily dose

* Based on individual patient response and tolerability.

a Total daily dose ( $\mathrm{mg} /$ day) should be divided as indicated by dose regimen to provide $\mathrm{mg} / \mathrm{dose}$

b Supplementary dose is a single additional dose.

OVERDOSAGE

Signs, Symptoms and Laboratory Findings of Acute Overdosage in Humans: The highest known dose of pregabalin received in the clinical development program was $15,000 \mathrm{mg}$ in 1 patient. The types of adverse events experienced by patients who received an overdose were not clinically different from other patients receivin recommended doses of pregabalin. In post-marketing experience the most commonly reported adverse events observed when pregabalin was taken in overdose (dose range from $800 \mathrm{mg} /$ day up to $11,500 \mathrm{mg}$ as a single dose) included affective disorder, somnolence, confusional state, depression, agitation, and restlessness.

Treatment or Management of Overdose: There is no specific antidote for overdose with pregabalin. If indicated elimination of unabsorbed drug may be attempted by emesis or gastric lavage; usual precautions should be observed to maintain the airway. General supportive care of the patient is indicated including monitoring of vit signs and observation of the clinical status of the patient. A Certified Poison Control Center should be contacted for up-to-date information on the management of overdose with pregabalin.

Hemodialysis: Standard hemodialysis procedures result in significant clearance of pregabalin (approximately $50 \%$ in 4 hours) and should be considered in cases of overdose. Although hemodialysis has not been performed in the few known cases of overdose, it may be indicated by the patient's clinical state or in patients with significant renal impairment.

\section{AVAILABILITY OF DOSAGE FORMS}

LYRICA is available in dosage strengths of $25 \mathrm{mg}, 50 \mathrm{mg}, 75 \mathrm{mg}, 100 \mathrm{mg}^{*}, 150 \mathrm{mg}, 200 \mathrm{mg}^{*}, 225 \mathrm{mg}^{*}$, and $300 \mathrm{mg}$ capsules.

* Not commercially available in Canada

For a copy of the Product Monograph or full Prescribing Information, please contact: Pfizer Canada Medical Information at 1-800-463-6001 or visit www.pfizer.ca

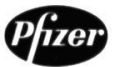

\section{Working together for a healthier world"'}

(-) 2009

Pfizer Canada Inc. TMpfizer Inc, used under license

$\begin{array}{ll}\text { Pfizer Canada Inc. } & \text { TMPfizer Inc, Used under license } \\ \text { Kirkland, Quebec } & \text { LYRICA C.P. Pharmaceuticals International C.V. } \\ \text { H9J 2M5 } & \text { Pfizer Canada Inc., Licensee }\end{array}$ 


\section{"Maxalt' \\ rizatriptan benzoate tablets}

\section{"Maxalt RPD'}

\section{Prescribing Summary}

\section{Patient Selection Criteria}

THERAPEUTIC CLASSIFICATION: 5-HT, Receptor Agonist INDICATIONS AND CLINICAL USE

\section{Adults}

MAXALT ${ }^{\circledR}$ is indicated for acute treatment of migraine attacks with or without aura in adults. MAXALT ${ }^{\circledR}$ is not intended for the prophylactic therapy of migraine or for use in the management of hemiplegic, ophthalmoplegic or basilar migraine (see CONTRAINDICATIONS in the Supplemental Product Information section). Safety and effectiveness of MAXALT ${ }^{\oplus}$ have not been established for cluster headache which is present in an older, predominantly male population.

\section{Pediatrics ( $<18$ years of age)}

The safety and efficacy of MAXALT ${ }^{\circledR}$ has not been established in patients under 18 years of age and its use in this age group is not recommended (see WARNINGS AND PRECAUTIONS)

\section{Geriatrics ( $>65$ years of age)}

The safety and effectiveness of MAXALT ${ }^{\circledR}$ has not been adequately studied in individuals over 65 years of age. Its use in this age group is, therefore, not recommended (see WARNINGS AND PRECAUTIONS)

\section{Special Populations and Conditions}

For use in special populations ( see Supplemental Product Information, WARNINGS AND PRECAUTIONS, Special Populations and Conditions)

\section{CONTRAINDICATIONS}

MAXALT ${ }^{\circledast}$ is contraindicated in patients with history, symptoms, or signs of ischemic cardiac, cerebrovascula or peripheral vascular syndromes, valvular heart disease or cardiac arrhythmias (especially tachycardias). In addition, patients with other significant underlying cardiovascular diseases (e.g., atherosclerotic disease congenital heart disease) should not receive MAXALT ${ }^{\oplus}$ Ischemic cardiac syndromes include, but are not restricted to, angina pectoris of any type (e.g., stable angina of effort and vasospastic forms of angina such as the Prinzmetal's variant), all forms of myocardial infarction, and silent myocardial ischemia. Cerebrovascular syndromes include, but are not limited to, strokes of any type as well as transient ischemic attacks (TIAs).

Peripheral vascular disease includes, but is not limited to, ischemic bowel disease, or Raynaud's syndrome (see WARNINGS AND PRECAUTIONS).

Because MAXALT ${ }^{\circledast}$ may increase blood pressure, it is contraindicated in patients with uncontrolled or severe hypertension (see WARNINGS AND PRECAUTIONS).

MAXALT $^{\circledR}$ is contraindicated within 24 hours of treatment with another $5-\mathrm{HT}_{1}$ agonist, or an ergotamine-containing or ergot-type medication like dihydroergotamine or methysergide.

MAXALT ${ }^{\oplus}$ is contraindicated in patients with hemiplegic, ophthalmoplegic or basilar migraine.

Concurrent administration of MAO inhibitors or use of rizatriptan within 2 weeks of discontinuation of MAO inhibitor therapy is contraindicated (see Drug Interactions).

Because there are no data available, MAXALT ${ }^{\odot}$ is contraindicated in patients with severe hepatic impairment.
MAXALT ${ }^{-}$is contraindicated in patients who are hypersensitive to rizatriptan or any component of the formulation.

\section{Safety Information}

\section{WARNINGS AND PRECAUTIONS}

\section{General}

MAXALT ${ }^{\circledast}$ should only be used where a clear diagnosis of migraine has been established.

For a given attack, if a patient has no response to the first dose of rizatriptan, the diagnosis of migraine should be reconsidered before administration of a second dose.

\section{Psychomotor Effect}

Dizziness, somnolence and asthenia/fatigue were expe rienced by some patients in clinical trials with MAXALT (see ADVERSE EVENTS). Patients should be advised to avoid driving a car or operating hazardous machinery until they are reasonably certain that MAXALT ${ }^{\circledR}$ does not adversely affect them.

\section{Cardiovascular}

Risk of Myocardial Ischemia and/or Infarction and Other Adverse Cardiac Events

MAXALT ${ }^{\circledast}$ has been associated with transient chest and or neck pain and tightness which may resemble angina pectoris. Following the use of other $5-\mathrm{HT}_{1}$ agonists in rare cases these symptoms have been identified as being the likely result of coronary vasospasm or myocardial ischemia. Rare cases of serious coronary events or arrhythmia have occurred following use of other 5- $\mathrm{HT}_{1}$ agonists, and may therefore also occu with MAXALT ${ }^{\oplus}$. Because of the potential of this class of compounds (5- $\mathrm{HT}_{1 \mathrm{~B} / 10}$ agonists) to cause coronary vasospasm, MAXALT ${ }^{\circledast}$ should not be given to patients with documented ischemic or vasospastic coronary artery disease (see CONTRAINDICATIONS). It is strongly recommended that MAXALT ${ }^{\circledR}$ not be given to patients in whom unrecognized coronary artery disease (CAD) is predicted by the presence of risk factors (e.g., hypertension, hypercholesterolemia, smoker, obesity, diabetes strong family history of CAD, female with surgical or physiological menopause, or male over 40 years of age) unless a cardiovascular evaluation provides satisfactory clinical evidence that the patient is reasonably free of coronary artery and ischemic myocardial disease or other significant underlying cardiovascular disease. The sensitivity of cardiac diagnostic procedures to detect cardiovascular disease or predisposition to coronary artery vasospasm is unknown. If, during the cardiovascular evaluation, the patient's medical history, electrocardiographic or other investigations revea findings indicative of, or consistent with, coronary artery vasospasm or myocardial ischemia, MAXALT ${ }^{\circledR}$ should not be administered (see CONTRAINDICATIONS)

For patients with risk factors predictive of CAD, who are considered to have a satisfactory cardiovascular evaluation, the first dose of rizatriptan should be administered in the setting of a physician's office or similar medically staffed and equipped facility. Because cardiac ischemia can occur in the absence of clinical symptoms, consideration should be given to obtaining on the first occasion of use an electrocardiogram (ECG) during the interval immediately following MAXALT ${ }^{\circledR}$, in these patients with risk factors. However, an absence of drug-induced cardiovascular effects on the occasion of the initial dose does not preclude the possibility of such effects occurring with subsequent administrations.

Intermittent long-term users of MAXALT ${ }^{\circledR}$ who have or acquire risk factors predictive of CAD, as described above, should receive periodic interval cardiovascular evaluation as they continue to use MAXALT ${ }^{\circledR}$.

If symptoms consistent with angina occur after the use of MAXALT ${ }^{\circledR}$, ECG evaluation should be carried out to look for ischemic changes.

The systematic approach described above is intended to reduce the likelihood that patients with unrecognized cardiovascular disease will be inadvertently exposed to MAXALT
Discomfort in the chest, neck, throat and jaw (including pain, pressure, heaviness and tightness) has been reported after administration of rizatriptan. Because drugs in this class may cause coronary artery vasospasm, patients who experience signs or symptoms suggestive of angina following dosing should be evaluated for the presence of CAD or a predisposition to Prinzmetal's variant angina before receiving additional doses of medication, and should be monitored electrocardiographically if dosing is resumed and similar symptoms recur. Similarly, patients who experience other symptoms or signs suggestive of decreased arterial flow, such as ischemic bowel syndrome or Raynaud's syndrome following MAXALT ${ }^{\circledast}$ administration should be evaluated for atherosclerosis or predisposition to vasospasm (see CONTRAINDICATIONS).

\section{Cardiac Events and Fatalities Associated with 5-HT,} Agonists

MAXALT ${ }^{\circledR}$ may cause coronary artery vasospasm. Serious adverse cardiac events, including acute myocardial infarction, life-threatening disturbances of cardiac rhythm, and death have been reported within a few hours following the administration of $5-\mathrm{HT}_{1}$ agonists. Considering the extent of use of $5-\mathrm{HT}_{1}$ agonists in patients with migraine, the incidence of these events is extremely low.

\section{Premarketing Experience with MAXALT}

Among the approximately 4200 patients who were treated with at least a single oral dose of either 5 or $10 \mathrm{mg}$ rizatriptan in premarketing clinical trials of MAXALT ${ }^{\circledR}$, electrocardiac adverse experiences were observed in 33 patients. One patient was reported to have chest pain with possible ischemic ECG changes following a single dose of $10 \mathrm{mg}$.

\section{Postmarketing Experience with MAXALT}

Serious cardiovascular events have been reported in association with the use of MAXALT ${ }^{\circledR}$. The uncontrolled nature of postmarketing surveillance, however, makes it impossible to determine definitively the proportion of reported cases that were actually caused by MAXALT ${ }^{\circledast}$ or to reliably assess causation in individual cases.

Cerebrovascular Events and Fatalities Associated with 5-HT, Agonists

Cerebral hemorrhage, subarachnoid hemorrhage, stroke, and other cerebrovascular events have been reported in patients treated with $5-\mathrm{HT}_{1}$ agonists; and some have resulted in fatalities. In a number of cases, it appears possible that the cerebrovascular events were primary, the agonist having been administered in the incorrect belief that the symptoms experienced were a consequence of migraine, when they were not. Before treating migraine headaches with MAXALT ${ }^{\circledast}$ in patients not previously diagnosed as migraineurs, and in migraineurs who present with atypical symptoms, care should be taken to exclude other potentially serious neurological conditions. If a patient does not respond to the first dose, the opportunity should be taken to review the diagnosis before a second dose is given. It should be noted that patients with migraine may be at increased risk of certain cerebrovascular events (e.g., stroke, hemorrhage, transient ischemic attack).

\section{Special Cardiovascular Pharmacology Studies with} Another 5-HT, Agonist

In subjects $(n=10)$ with suspected coronary artery disease undergoing angiography, a 5- $\mathrm{HT}_{1}$ agonist at a subcutaneous dose of $1.5 \mathrm{mg}$ produced an $8 \%$ increase in aortic blood pressure, an $18 \%$ increase in pulmonary artery blood pressure, and an $8 \%$ increase in systemic vascular resistance. In addition, mild chest pain or tightness was reported by four subjects. Clinically significant increases in blood pressure were experienced by three of the subjects (two of whom also had chest pain/discomfort). Diagnostic angiogram results revealed that 9 subjects had normal coronary arteries and one had insignificant coronary artery disease.

In an additional study with this same drug, migraine patients $(n=35)$ free of cardiovascular disease were subjected to assessments of myocardial perfusion by positron emission tomography while receiving a subcutaneous $1.5 \mathrm{mg}$ dose in the absence of a migraine attack. Reduced coronary vasodilatory reserve $(\sim 10 \%)$, increased coronary resistance ( 20\%), and decreased hyperemic myocardial blood flow 
$(-10 \%)$ were noted. The relevance of these findings to the use of the recommended oral dose of this $5-\mathrm{HT}_{1}$ agonist is not known.

Similar studies have not been done with MAXAL ${ }^{-3}$. However, owing to the common pharmacodynamic actions of $5-\mathrm{HT}_{1}$ agonists, the possibility of cardiovascular effects of the nature described above should be considered for any agent of this pharmacological class.

\section{Other Vasospasm-Related Events}

5-HT, agonists may cause vasospastic reactions other than coronary artery vasospasm. Extensive postmarket experience has shown the use of another $5-\mathrm{HT} \mathrm{T}_{1}$ agonist to be associated with rare occurrences of peripheral vascular ischemia and colonic ischemia with abdominal pain and bloody diarrhea.

\section{Increase in Blood Pressure}

Significant elevation in blood pressure, including hypertensive crisis, has been reported on rare occasions in patients receiving $5-H T$, agonists with and without a history of hypertension. In healthy young male and female subjects who received maximal doses of MAXALT ${ }^{\otimes}$ (10 mg every 2 hours for 3 doses), slight increases in blood pressure (approximately $2-3 \mathrm{mmHg}$ ) were observed. Rizatriptan is contraindicated in patients with uncontrolled or severe hypertension (see CONTRAINDICATIONS). In patients with controlled hypertension, MAXALT ${ }^{\circledR}$ should be administered with caution, as transient increases in blood pressure and peripheral vascular resistance have been observed in a small portion of patients.

\section{Endocrine and Metabolism \\ Phenylketonurics}

Phenylketonuric patients should be informed that MAXALT $\mathrm{RPD}^{\circledR}$ Wafers contain phenylalanine (a component of aspartame). Each $5 \mathrm{mg}$ wafer contains $1.05 \mathrm{mg}$ phenylalanine, and each $10 \mathrm{mg}$ wafer contains $2.10 \mathrm{mg}$ phenylalanine.

\section{Hepatic/Biliary/Pancreatic}

Rizatriptan should be used with caution in patients with moderate hepatic insufficiency due to an increase in plasma concentrations of approximately $30 \%$ (see ACTION AND CLINICAL PHARMACOLOGY, Special Populations and Conditions in the Product Monograph and DOSAGE AND ADMINISTRATION). Since there are no data in patients with severe hepatic impairment, rizatriptan is contraindicated in this population (see CONTRAINDICATIONS and DOSAGE AND ADMINISTRATION).

\section{Immune}

Rare hypersensitivity (anaphylaxis/anaphylactoid) reactions may occur in patients receiving $5-\mathrm{HT}_{1}$ agonists such as MAXALT ${ }^{\boxplus}$. Such reactions can be life threatening or fatal. In general, hypersensitivity reactions to drugs are more likely to occur in individuals with a history of sensitivity to multiple allergens. Owing to the possibility of cross-reactive hypersensitivity reactions, MAXALT ${ }^{\text {B }}$ should not be used in patients having a history of hypersensitivity to chemicallyrelated 5-HT, receptor agonists.

\section{Neurologic}

Care should be taken to exclude other potentially serious neurologic conditions before treating headache in patients not previously diagnosed with migraine or who experience a headache that is atypical for them. There have been rare reports where patients received $5-\mathrm{HT}_{1}$ agonists for severe headache that were subsequently shown to have been secondary to an evolving neurological lesion. For newly diagnosed patients or patients presenting with atypical symptoms, the diagnosis of migraine should be reconsidered if no response is seen after the first dose of MAXALT ${ }^{\circledR}$.

\section{Seizures}

Caution should be observed if MAXALT ${ }^{\oplus}$ is to be used in patients with a history of epilepsy or structural brain lesions which lower the convulsion threshold. There have been very rare reports of seizures following administration of MAXALT in patients with or without risk factors or previous history of seizures (see ADVERSE REACTIONS, Post-Marketing Adverse Reactions, Nervous System in the Supplemental Product Information)

\section{Ophthalmologic}

\section{Binding to Melanin-Containing Tissues}

The propensity for rizatriptan to bind melanin has not been investigated. Based on its chemical properties, rizatriptan may bind to melanin and accumulate in melanin-rich tissue (e.g. eye) over time. This raises the possibility that rizatriptan could cause toxicity in these tissues after extended use There were, however, no adverse ophthalmologic changes related to treatment with rizatriptan in the one-year dog toxicity study. Although no systematic monitoring of ophthalmologic function was undertaken in clinical trials, and no specific recommendations for ophthalmologic monitoring are offered, prescribers should be aware of the possibility of long-term ophthaimologic effects.

Renal

Rizatriptan should be used with caution in dialysis patients due to a decrease in the clearance of rizatriptan, resulting in approximately $44 \%$ increase in plasma concentrations (see ACTION AND CLINICAL PHARMACOLOGY, Specia Populations and Conditions in the Product Monograph, and DOSAGE AND ADMINISTRATION)

\section{Selective Serotonin Reuptake Inhibitors/Serotonin} Norepinephrine Reuptake Inhibitors and Serotonin Syndrome

Cases of life-threatening serotonin syndrome have been reported during combined use of selective serotonin reuptake inhibitors (SSRIs)/serotonin norepinephrine reuptake inhibitors (SNRIS) and triptans. If concomitant treatment with MAXALT ${ }^{\oplus}$ and SSRIs (e.g., sertraline, escitalopram oxalate, and fluoxetine) or SNRIs (e.g., venlafaxine, duloxetine) is clinically warranted, careful observation of the patient is advised, particularly during treatment initiation and dose increases. Serotonin syndrome symptoms may include mental status changes (e.g., agitation, hallucinations, coma), autonomic instability (e.g. tachycardia, labile blood pressure, hyperthermia), neuromuscular aberrations (e.g., hyperreflexia, incoordination) and/or gastrointestina symptoms (e.g, nausea, vomiting, diarrhea) (see DRUG INTERACTIONS)

\section{Special Populations and Conditions}

For use in special populations (see Supplemental Product Information, WARNINGS AND PRECAUTIONS, Special Populations and Conditions).

\section{ADVERSE REACTIONS}

\section{(see Supplemental Product Information for full listing)}

\section{Adverse Drug Reaction Overview}

Serious cardiac events, including some that have been fatal, have occurred following use of 5- $\mathrm{HT}_{1}$ agonists. These events are extremely rare and most have been reported in patients with risk factors predictive of CAD. Events reported have included coronary artery vasospasm, transient myocardial ischemia, myocardial infarction, ventricular tachycardia, and ventricular fibrillation (see CONTRAINDICATIONS, WARNINGS AND PRECAUTIONS).

\section{Long-Term Safety}

In long-term extension studies, a total of 1854 patients treated 16,150 migraine attacks with MAXALT ${ }^{\circledR} \mathrm{mg}$ Tablets and 24,043 attacks with MAXALT ${ }^{\circledR} 10 \mathrm{mg}$ Tablets over a period of up to 1 year. In general, the types of clinical adverse experiences observed in the extension studies were similar to those observed in the acute studies. However, the incidences of most clinical adverse events were approximately 3-fold higher in extension, as expected, based on increased observation time. The most common adverse events per attack (defined as occurring at an incidence of at least 1\%) for MAXAL ${ }^{-3} 5 \mathrm{mg}$ and $10 \mathrm{mg}$. respectively, were as follows: nausea $(3 \%, 4 \%)$, dizziness $(2 \%, 2 \%)$, somnolence $2 \%, 4 \%)$, asthenia/fatigue $(2 \%, 2 \%)$. headache $(1 \%, 2 \%)$, vomiting $(1 \%,<1 \%)$, chest pain $(<1 \%$, $1 \%)$ and paresthesia $(<1 \%, 2 \%)$. Due to the lack of placebo controls in the extension studies, the role of MAXALT' in causation cannot be reliably determined.

To report a suspected adverse reaction, please contact Merck Frosst Canada Ltd. by:

Toll-free telephone: 1-800-567-2594

Toll-free fax: 1-877-428-8675
By regular mail: Merck Frosst Canada Ltd, P.O. Box 1005 , Pointe-Claire - Dorval, QC H9R 4P8

\section{DRUG INTERACTIONS}

\section{Ergot-Containing Drugs}

Ergot-containing drugs have been reported to cause prolonged vasospastic reactions. Because there is a theoretical basis that these effects may be additive, use of ergotamine-containing or ergot-type medications (like dihydroergotamine or methysergide) and rizatriptan within 24 hours is contraindicated (see CONTRAINDICATIONS)

\section{Monoamine Oxidase Inhibitors}

Rizatriptan is principally metabolized via monoamine oxidase, 'A' subtype (MAO-A). In a drug interaction study when MAXALT $10 \mathrm{mg}$ was administered to subjects $(n=12)$ receiving concomitant therapy with the selective reversible MAO-A inhibitor, moclobemide $150 \mathrm{mg}$ t.i.d. there were mean increases in rizatriptan $A U C$ and $C_{\max }$ of $119 \%$ and $41 \%$, respectively; and the AUC of the active $\mathrm{N}$-monodesmethyl metabolite of rizatriptan was increased more than $400 \%$. The interaction would be expected to be greater with irreversible MAO inhibitors. Drug interaction studies were not conducted with selective MAO-B inhibitors.

The specificity of MAO-B inhibitors diminishes with higher doses and varies among patients. Therefore, $\mathrm{CO}$-administration of rizatriptan in patients taking MAO-A or MAO-B inhibitors is contraindicated (see CONTRAINDICATIONS).

\section{Nadolol/Metoprolol}

In a drug interactions study, effects of multiple doses of nadolol $80 \mathrm{mg}$ or metoprolol $100 \mathrm{mg}$ every 12 hours on the pharmacokinetics of a single dose of $10 \mathrm{mg}$ rizatriptan were evaluated in healthy subjects $(n=12)$. No pharmacokinetic interactions were observed.

\section{Oral Contraceptives}

In a study of concurrent administration of an oral contraceptive during 6 days of administration of MAXALT (10-30 $\mathrm{mg} /$ day) in healthy female volunteers $(n=18)$, rizatriptan did not affect plasma concentrations of ethinyl estradiol or norethindrone.

\section{Other 5-HT, Agonists}

The administration of rizatriptan with other $5-\mathrm{HT}_{1}$ agonists has not been evaluated in migraine patients.

Because their vasospastic effects may be additive, Co-administration of rizatriptan and other $5-\mathrm{HT}_{1}$ agonists within 24 hours of each other is contraindicated (see CONTRAINDICATIONS)

\section{Propranolo}

MAXALT ${ }^{\circledast}$ should be used with caution in patients receiving propranolol, since the pharmacokinetic behavior of rizatriptan during co-administration with propranolol may be unpredictable. In a study of concurrent administration of propranolol $240 \mathrm{mg} /$ day and a single dose of rizatriptan $10 \mathrm{mg}$ in healthy subjects ( $\mathrm{n}=11$ ), mean plasma AUC and $\mathrm{C}_{\max }$ for rizatriptan were increased by $70 \%$ and $75 \%$, respectively, during propranolol administration. In one subject, a 4-fold increase in AUC and 5 -fold increase in $\mathrm{C}_{\max }$ was observed. This subject was not distinguishable from the others based on demographic characteristics. The AUC of the active $\mathrm{N}$-monodesmethyl metabolite of rizalriptan was not affected by propranolol (see DOSAGE AND ADMINISTRATION).

Selective Serotonin Reuptake Inhibitors / Serotonin Norepinephrine Reuptake Inhibitors and Serotonin Syndrome

Cases of life-threatening serotonin syndrome have been reported in post-marketing experience during combined use of selective serotonin reuptake inhibitors (SSRIs) or serotonin norepinephrine reuptake inhibitors (SNRIs) and triptans (see WARNINGS AND PRECAUTIONS)

In a pharmacokinetic study with paroxetine and rizatriptan, paroxetine had no influence on the plasma levels of rizatriptan.

\section{Food}

Interactions with food have not been studied. Food has no significant effect on the bioavailability of rizatriptan but delays the time to reach peak concentration by an hour. In clinical trials, MAXALT ${ }^{\circledR}$ was administered without regard to food. 


\section{OD Administration}

\section{DOSAGE AND ADMINISTRATION}

(see Product Monograph for complete information)

\section{Dosing Considerations}

MAXALT ${ }^{-3}$ is recommended only for the acute treatment of migraine attacks. MAXALT ${ }^{\circledast}$ should not be used prophylactically. Controlled trials have not established the effectiveness of a second dose if the initial dose is ineffective.

The safety of treating, on average, more than four headaches in a 30-day period has not been established.

\section{Recommended Dose and Dosage Adjustment}

\section{ADULTS}

\section{MAXALT ${ }^{\star}$ Tablets and MAXALT RPD ${ }^{\star}$ Wafers}

The recommended single adult dose is $5 \mathrm{mg}$. The maximum recommended single dose is $10 \mathrm{mg}$. There is evidence that the $10 \mathrm{mg}$ dose may provide a greater effect than the $5 \mathrm{mg}$ dose (see CLINICAL TRIALS in the Product Monograph). The choice of dose should therefore be made on an individual basis, weighing the possible benefit of the $10 \mathrm{mg}$ dose with the potential risk for increased adverse events.

For MAXALT RPD Wafers, administration with liquid is not necessary. The water is packaged in a blister within an outer aluminum pouch. Patients should be instructed not to remove the blister from the outer pouch until just priof to dosing. The blister pack should then be peeled open with dry hands and the wafer placed on the tongue, where it will dissolve and be swallowed with the saliva.

\section{Redosing}

Doses should be separated by at least 2 hours; no more than a totat of $20 \mathrm{mg}$ (Tablets or Wafers) should be taken in any 24-hour period.

\section{Patients receiving propranolol}

A single $5 \mathrm{mg}$ dose of MAXALT ${ }^{\circledast}$ should be used. In no instances should the total daily dose exceed $10 \mathrm{mg}$ per day, given in two doses, separated by at least two hours (see DRUG INTERACTIONS).

\section{Renal Impairment}

In hemodialysis patients with severe renal impairment (creatinine clearance $<2 \mathrm{~mL} / \mathrm{min} / 1.73 \mathrm{~m}^{2}$ ), the AUC of rizatriptan was approximately $44 \%$ greater than in patients with normal renal function (see ACTION AND CLINICAL PHARMACOLOGY, Special Populations and Conditions in the Product Monograph). Consequently, if treatment is deemed advisable in these patients, the $5 \mathrm{mg}$ MAXALT Tablet or Wafer should be administered. No more than a total of $10 \mathrm{mg}$ should be taken in any 24-hour period. Repeated dosing in renally impaired patients has not been evaluated.

\section{Hepatic Impairment}

MAXALT is contraindicated in patients with severe hepatic impairment (Child-Pugh grade $\mathrm{C}$ ) due to the absence of safety data. Plasma concentrations of rizatriptan were approximately $30 \%$ greater in patients with moderate hepatic insufficiency (see ACTION AND CLINICAL PHARMACOLOGY, Special Populations and Conditions in the Product Monograph). Consequently, if treatment is deemed advisable in the presence of moderate hepatic impairment the $5 \mathrm{mg}$ MAXALT ${ }^{\circledR}$ Tablet or Wafer should be administered No more than a total of $10 \mathrm{mg}$ should be taken in any 24-hour period. Repeated dosing in hepatically impaired patients has not been evaluated.

\section{Patients with Hypertension}

MAXAL ${ }^{\circledast}$ should not be used in patients with uncontrolled or severe hypertension. In patients with mild to moderate controlled hypertension, patients should be treated cautiously at the lowest effective dose.

\section{OVERDOSAGE}

No overdoses of MAXALT were reported during clinical trials.

Rizatriptan $40 \mathrm{mg}$ (administered as either a single dose or as two doses with a 2-hour interdose interval) was generally well tolerated in over 300 patients; dizziness and somnolence were the most common drug-related adverse effects.

In a clinical pharmacology study in which 12 subjects received rizatriptan, at total cumulative doses of $80 \mathrm{mg}$ (given within four hours), two subjects experienced syncope and/or bradycardia. One subject, a female aged 29 years, developed vomiting, bradycardia, and dizziness beginning three hours after receiving a total of $80 \mathrm{mg}$ rizatriptan (administered over two hours); a third degree AV block, responsive to atropine, was observed an hour after the onset of the other symptoms. The second subject, a 25-year-old male, experienced transient dizziness, syncope, incontinence, and a 5-second systolic pause (on ECG monitor) immediately after a painful venipuncture. The venipuncture occurred two hours after the subject had received a total of $80 \mathrm{mg}$ rizatriptan (administered over four hours).

In addition, based on the pharmacology of rizatriptan, hypertension or other more serious cardiovascular symptoms could occur after overdosage. Gastrointestinal decontamination (i.e., gastric lavage followed by activated charcoal) should be considered in patients suspected of an overdose with MAXALT ${ }^{\oplus}$. The elimination half-life of rizatriptan is 2 to 3 hours (see ACTION AND CLINICAL PHARMACOLOGY in the Product Monograph). Clinical and electrocardiographic monitoring should be continued for at least 12 hours, even if clinical symptoms are not observed

There is no specific antidote to rizatriptan. In cases of severe intoxication, intensive care procedures are recommended, including establishing and maintaining a patent airway, ensuring adequate oxygenation and ventilation, and monitoring and support of the cardiovascular system.

The effects of hemo- or peritoneal dialysis on serum concentrations of rizatriptan are unknown.

\section{Supplemental Product Information WARNINGS AND PRECAUTIONS}

\section{Special Populations and Conditions}

Pregnant Women: in a reproduction study in rats, birth weights and pre- and post-weaning weight gain were reduced in the offspring of temales treated prior to anc during mating and throughout gestation and lactation. These plas ocu plasma drug exposuses were 22 and 337 times, respectuen, the exposure $20 \mathrm{mg}$ ). The develcpmental no-effect dose was equivalent to 2.25 times human $20 \mathrm{mg})$. The develcpmente

In embryofetal development studies, no teratogenic effects were observed when pregnant rats and rabbits were administered doses at the equivalent of 337 times and 168 times, respectively the hurnan MRDD, during organogenesis. However, etal weights were decreased in conjunction with decreased materna weight gain at these same doses. The deve.opmental no-effect dose in both rats and rabbits was 22 times the human MRDO

There are no adequate and well-controlled studies in pregnant women therefore, rizatriptan should be used during pregnancy only if the potentia benefit justifies the potential risk to the fetus.

\section{Impairment of Fertility}

In a fertlity study in rats, altered estrus cyclicity and delays in time to mating were observed in females treated oraly with an equivalent of 337 times the maximum recommended daily dose (MRDD) of $20 \mathrm{mg}$ in humans. The no-effect dose was 22 times the MRDD. There was no impairment of fertility or reproductive periormance in male rats treated with up to 825 times the MRDD.

Nursing Women: It is not known whether this drug is excreted in human mik. Because many drugs are excreted in human milk, caution should be exercised when MAXALT is administered to women who are breast-feeding. than maternal plasma levels.

Pediatrics ( $<18$ years of age): MAXALT' is not recomrended for use in patients under 18 years of age. In a randomized placebo-controlled trial 291 adolescent migraineurs, aged 12-17 years, the eflicacy of MAXALT monograph).

Geriatrics ( $>65$ years of age): The safety and effectiveness of MAXALT has not been adequately studied in individuals over 65 years of age. The ris of adverse reactions to this drug may be greater in elderly patients, as they are more likely to have decreased hepatic function, be at higher risk for $C A D$, an experience blood pressure increases that may be more pronounced. Clinica studies with MAXALT
65 years of age $(n=17)$. Its use in this age group is, therefore, not recom65 years
mended.

\section{Special Disease Conditions:}

MAXALT ${ }^{\text {Thi }}$ should be administered with caution to patients with diseases that or excretion of drugs isee ACTION AN CLINICAL PHARMACOLOGY, Special Populations and Conditions in the product monograph)

Monitoring and Laboratory Tests

No specific laboratory tests are recommended for monitoring patients prior to and/or after treatment with MAXALT

\section{ADVERSE REACTIONS}

\section{Glinical Trial Adverse Drug Reactions}

Because clinicai trials are conducted under very specific conditions the adverse reaction rates observed in the clinical trials may not reflect the rates observed in practice and should nol be compared to the rates in the chinical trials of

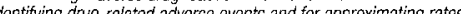
Experience in Controlled Clinical Trials with MAXALT ${ }^{\text {क }}$

\section{Typical 5-HT Agonist Adverse Reactions $^{2}$}

AS wth other $5-\mathrm{HT}_{1}$ agonists, MAXALT has been assoclated with sensations o in any part of the body including the chest, throat. neck, jaw and upper limb. Acute Safety

Adverse experiences to rizatriptan were assessed in controlied clinical trials that included over 3700 patients who received single or multiple doses of MAXALT ablets. The most common adverse events during treatment with MAXALT were asthenia/fatigue, somnolence, pain/pressure sensation and dizziness. These events appeared to be dose-related. In long-term extension studies where patients were allowed to treat multipie attacks for up to 1 year, $4 \%$

Tables 1 and 2 list the adverse events regardless of drug relationship (incidence $\geq 1 \%$ and greater than placebo) atter a single dose of MAXALI Tablets an MAXALT RPD Wafers, respectively. Most of the adverse events appear to be dose-related. The events cited reflect experience gained under closely monitored conditions of clinical trials in a highly selected patient population In actual clinical practice or in other clinical trials, these frequency estimate may not apply, as the conditions of use, reporting behavior, and the kinds of
patients treated may differ.

Table 1

\begin{tabular}{|c|c|c|c|}
\hline & \multicolumn{3}{|c|}{$\%$ of Patients } \\
\hline & Placebo & $\begin{array}{c}\text { MAXALT } \\
5 \mathrm{mg}\end{array}$ & $\begin{array}{c}\text { MAXALI }^{*} \\
10 \mathrm{mg}\end{array}$ \\
\hline Number of Patients & 627 & 977 & 1167 \\
\hline \multicolumn{4}{|c|}{ Symptoms of Potentially Cardiac Origin } \\
\hline Upper Limb Sensations" & 1.3 & 1.7 & 1.8 \\
\hline Chest Sensations* & 1.0 & 1.6 & 3.1 \\
\hline Neck/Throat/Jaw Sensations* & 0.6 & 1.4 & 2.5 \\
\hline \multicolumn{4}{|l|}{ Body as a Whole } \\
\hline Asthenia/Fatigue & 2.1 & 4.2 & 6.9 \\
\hline $\begin{array}{l}\text { Abdominal Pain } \\
\text { Digestive System }\end{array}$ & 1.0 & 1.7 & 2.2 \\
\hline Nausea & 3.5 & 4.1 & 5.7 \\
\hline Dry Mouth & 1.3 & 2.6 & 3.0 \\
\hline Vomiting & 2.1 & 1.6 & 2.3 \\
\hline \multicolumn{4}{|l|}{ Nervous System } \\
\hline Dizziness & 4.5 & 4.2 & 8.9 \\
\hline Somnolence & 3.5 & 4.2 & 8.4 \\
\hline Headache & 0.8 & 1.8 & 2.1 \\
\hline Paresthesia & 1.0 & 1.5 & 2.9 \\
\hline & 1.0 & 1.3 & 0.3 \\
\hline Insomnia & 0.3 & 1.0 & 0.3 \\
\hline \multicolumn{4}{|l|}{ Skin and Skin Appendage } \\
\hline
\end{tabular}

"The term "sensations" encompasses adverse events described as pain, discomfort, pressure, heaviness, constriction, tightness, heatburning sensation, paresthesia, numbness, tingling, weakness and strange sensations.

Data from Studies 022, 025, 029 and 030 .

Table 2 After 2 (2 $1 \%$ and Greater than Placebo) of Adverse Experiences After a Single Dose of MAXALT RPD ${ }^{\infty}$ Wafers or Placebo (Prior to Subsequent Dose) in Phase III Controlled Clinical Trials ${ }^{\dagger}$

\begin{tabular}{|c|c|c|c|}
\hline & \multicolumn{3}{|c|}{$\%$ of Patients } \\
\hline & Placebo & $\begin{array}{c}\text { MAXALT } \\
\text { RPD }^{\circ} \\
5 \mathrm{mg}\end{array}$ & $\begin{array}{c}\text { MAXALT } \\
\text { RPD }^{\infty} \\
10 \mathrm{mg}\end{array}$ \\
\hline Number of Patients & 283 & 282 & 302 \\
\hline
\end{tabular}

\begin{tabular}{|c|c|c|c|}
\hline Number of Patients & 283 & 282 & 302 \\
\hline \multicolumn{4}{|c|}{ Symptoms of Potentially Cardiac Origin } \\
\hline Chest Sensations* & 0.4 & 1.4 & 1.7 \\
\hline Neck/throat/Jaw Sensations ${ }^{*}$ & 0.4 & 1.4 & 2.0 \\
\hline Tachycardia & 1.1 & 1.4 & 0.3 \\
\hline Upper Limb Sensations* & 0.4 & 0.7 & 2.0 \\
\hline Palpitations & 0.4 & 0.4 & 1.0 \\
\hline \multicolumn{4}{|l|}{ Body as a Whole } \\
\hline AstheniafFatigue & 0.4 & 2.1 & 3.6 \\
\hline \multicolumn{4}{|l|}{ Digestive System } \\
\hline Dry Mouth & 2.1 & 6.4 & 6.0 \\
\hline Náused & 5.7 & 6.4 & 7.0 \\
\hline Dyspepsia & 0.7 & 1.1 & 2.0 \\
\hline Acid Regurgitation & 0 & 1.1 & 0.7 \\
\hline Salivation Increase & 0 & 0 & 1.3 \\
\hline \multicolumn{4}{|l|}{ Musculoskeletal System } \\
\hline Regional Heaviness & 0 & 0 & 1.0 \\
\hline \multicolumn{4}{|l|}{ Nervous System } \\
\hline Dizziness & 3.9 & 6.4 & 8.6 \\
\hline Somnolence & 2.8 & 4.3 & 5.3 \\
\hline Headache & 0.7 & 1.8 & 2.0 \\
\hline Insomnia & 0 & 1.4 & 0.7 \\
\hline Paresthesia & 0.4 & 1.4 & 3.0 \\
\hline Hypesthesia & 0 & 1.4 & 0.7 \\
\hline Mental Acuity Decreased & 0 & 1.1 & 0.3 \\
\hline Tremor & 0.7 & 1.1 & 0 \\
\hline Nervousness & 0.4 & 1.1 & 0.7 \\
\hline \multicolumn{4}{|l|}{ Respiratory System } \\
\hline Pharyngeal Discomtort & 0 & 1.1 & 0.7 \\
\hline \multicolumn{4}{|l|}{ Skin and Skin Appendage } \\
\hline Sweating & 0.7 & 1.1 & 1.0 \\
\hline \multicolumn{4}{|l|}{ Special Senses } \\
\hline Taste Perversion & 1.1 & 1.4 & 2.3 \\
\hline Blurred Vision & 0 & 0.4 & 1.3 \\
\hline
\end{tabular}

"The term "sensations" encompasses adverse events described as pain, discomfort, pressure heaviness, constriction tightness, heat/buming sensation coresthesia, numbness, tingling, weakness and strange sensations.

tData from Studies 039 and 049

MAXALT was generally well-tolerated. Adverse experiences were typicaliy mild in intensity and were transient. The frequencies of adverse experiences in clinical triais did not increase when up to three doses were taken within 24 hours. The incidences of adverse experiences were not affected by age, assess the impact of race on the incidence of adverse events.

Other Events Observed in Association with the Administration

In the section that follows, the frequencies of less commonly reported adverse clinical events are presented. Because the reports include events observed in open studles, the role ol MaXAL in inelr causation cannot be rellably the termir. Furthermore, varlabity associated with adverse event reporting, the terminogy used to describe adverse events, eic. lintit the value of the the rumber and

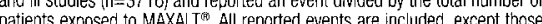


already listed in the previous table, those too general to be informative, and those not reasonably associated with the use of the drug. Events are furthe classified within body system categories and enumerated in order of decreasing frequency using the following definitions: frequent adverse events are those defined as those occurring in at least $1 / 100$ patients; infrequent adverse experiences are those occuing in $1 / 100$ to $1 / 1000$ patients, and rare adverse experiences are those

Body as a Whole

Frequent were warm sensations, chest pain and chills/cold sensations. Infrequent were heat sensitivity, facial edema, hangover effect abdomina distention, edema/swelling and malaise. Rare were fever, orthostatic effects, and syncope.

Cardiovascular

Frequent was palpitation. Infrequent were tachycardia, cold extremities thertension, arrhythmia, and bradycardia Rare were angina pectoris and blood pressure increased.

Digestive

Frequent was diarrhea. Infrequent were dyspepsia, thirst, acid regurgitation, dysphagia, constipation, flatulence, and tongue edema. Rare were anorexia, appetite increase, gastritis, paralysis (tongue), eructation and glosodynia.

Metabolic

Infrequent was dehydration.

Musculoskeletal

Infrequent were muscle weakness, stiffness, myalgia, muscle cramp, musculoskeletal pain, and arthralgia

Neurological/Psychiatric

Frequent were hypesthesia and mental acuity decreased. Infrequent were nervousness, vertigo, insomnia, anxiety, depression, euphoria, disorientation, ataxia, dysarthria, confusion, dream abnormality, gait abnormality, irritability, memory impairment, agitation, hyperesthesia, sleep disorder, speech disorder migraine and spasm. Rare were dysesthesia, depersonalization, akinesia/ bradykinesia, apprehension, hyperkinesia, hypersomnia, and hyporeflexia.

Respiratory

Frequent were dyspnea and pharyngeal discomfort. Infrequent were pharyngitis, irritation (nasal), congestion (nasal), dry throat, upper respiratory infection, yawning, respiratory congestion, dry nose, epistaxis, and sinus disorder pharyngeal edema.

Special Senses

Frequent was taste perversion. Infrequent were blurred vision, tinnitus, dry eyes, burning eye, eye pain, eye irritation, ear pain, and tearing. Rare were hyperacusis, smell perversion, photophobia, photopsia, itching eye, and eye

Skin and Skin Appendage

Infrequent were sweating, pruritus, rash, and urticaria. Rare were erythema, acne, and photosensitivity.

Urogenital System

Frequent was hot flashes. Infrequent were urinary frequency, polyuria, and menstruation disorder. Rare was dysuria.

The adverse experience profile seen with MAXALT RPD ${ }^{\circledR}$ Wafers was similar to that seen with MAXALI T Tablets.

Post-Market Adverse Drug Reactions

The following additional adverse reactions have been reported very rarely and most have been reported in patients with risk factors predictive of CAD

The following adverse reactions have also been reported:

Hypersensitivity: Hypersensitivity reaction, anaphylaxis/anaphylactoid reaction, angioedema (e.g., facial edema, tongue swelling, pharyngeal edema), wheezing, urticaria, rash, toxic epidermal necrolysis.

Nervous System: serotonin syndrome.

Seizures: There have been very rare reports of seizures following administratio of MAXALT in patients with or without risk factors or previous history of seizures (see WARNINGS AND PRECAUTIONS).

Musculoskeletal: facial pain.

Special Senses: Dysgeusia.

Vascular disorders: Peripheral vascular ischemia

Drug Abuse and Dependence

Although the abuse potential of MAXALT ${ }^{\circledast}$ has not been specifically assessed, no abuse of, tolerance to, withdrawal from, or drug-seeking behavior was observed in patients who received MAXALT ${ }^{\oplus}$ in clinical trials or their extensions. The 5-HT $T_{1010}$ agonists, as a class, have not been associated with drug abuse.

09, 09-a_122943

Product Monograph available at www.merckfrosst.com

or upon request at 1-800-567-2594

\section{(8) MERCK}

Merck Frosst Canada Ltd., Kirkland, Quebec, H9H 3L1

\section{KING MEDICAL}

\section{THE CANADIAN ELECTRODE PLACE}

- ALPINE BIOMED Mono/Conc. Needles

- AMBU Blue Sensor - Neuroline

- CHALGREN Needles • Bar/Ring/Clip

- KENDALL Adhesive - NuTab

- KING MEDICAL Cables \& Adapters

- MAVIDON Lemon Skin Prep

- MERIT CABLES Snap Button Cables

- PARKER LAB. Electrode Paste

- RADIANT Infrared Skin Thermometer

- 3M CANADA Micropore - Transpore

- D.O.WEAVER Ten20 • NuPrep

Clavis $^{\mathrm{TM}} \cdot$ Bo-ject $^{\mathrm{TM}} \cdot$ Chalgren $\cdot$ Inoject $^{\mathrm{TM}}$ Large stock of Hypodermic Needles

Tel 905-833-3545 Fax 905-833-3543

E-mail: soren@kingmedical.com Web Site: www.kingmedical.com

King Medical Ltd.

145 Kingsworth Road King City • Ontario L7B 1K1

\section{ADVERTISERS INDEX}

Athena

$\mathrm{OBC}$

CNSF Sponsors

IBC

Elekta

IFC

King Medical

Merck - Maxalt

A-17

Pfizer - Lyrica

A-5, A-14 to A-17

Scotia Bank
A-8, A-12, A-13

A-7

Job Postings

Lahey Clinic Neurosurgeon

A-11

University of Western

Ontario Pain Fellowship

A-11 

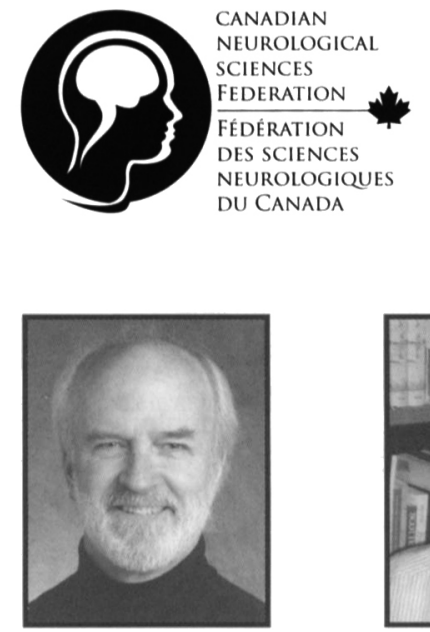

George Elleker

- CNSF President

- NSFC President

- CSCN Past President

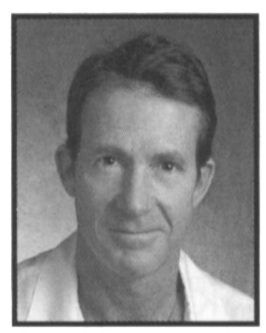

J. Max Findlay

- CNSF Board Member

- NSFC Board Member

- CNSS President

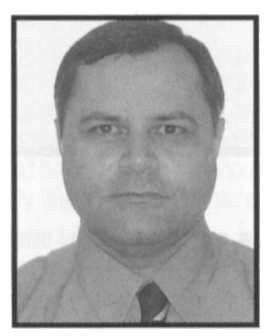

Seyed Mirsattari

- CNSF Board Member

- NSFC Board Member

- CSCN Vice-President

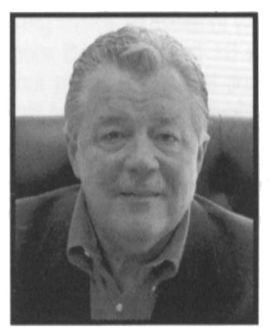

Dan Morin

- CEO

Non-voting

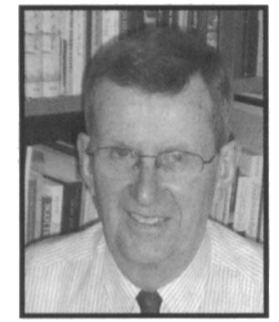

Garth Bray

- CNSF Vice-President

- NSFC Vice-President

- CNS Member

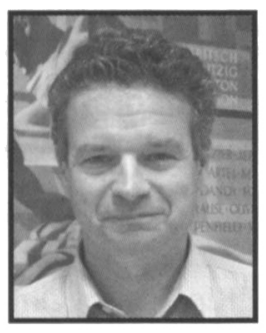

\section{Chris Wallace}

- CNSF Board Member

- NSFC Board Member

- CNSS Vice-President

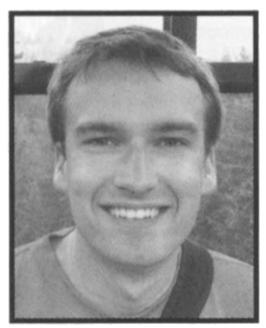

Trevor Steve

- CNSF Board Member

- NSFC Board Member

- Residents' Rep. CNS

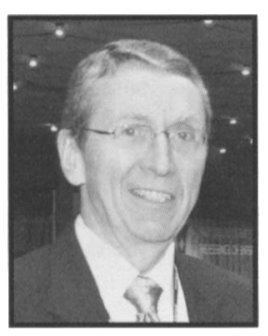

G. Bryan Young

- Journal Editor-in-Chief - CNS \& CSCN Member

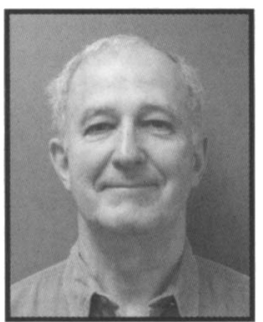

\section{Derek Fewer}

- CNSF Vice-President

- NSFC Vice-President

- CNSS Past President

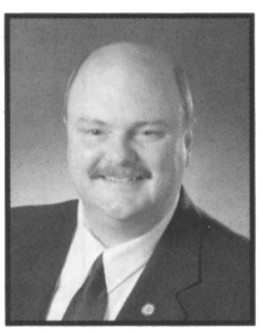

Lyle Weston

- CNSF Board Member

- NSFC Board Member

- CNS President

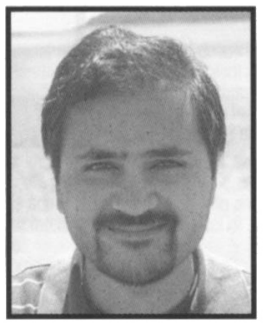

Shobhan Vachhrajani

- Residents' Rep. CNSS

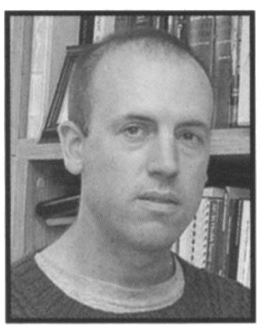

Michael Hill

- CNSF Scientific Program

Committee Chair

- CNS Member

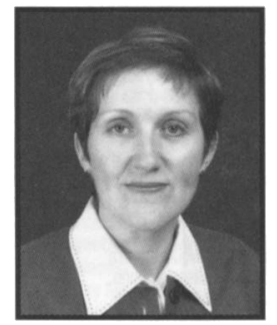

Mary Connolly

- CNSF Board Member

- NSFC Board Member

- CACN President

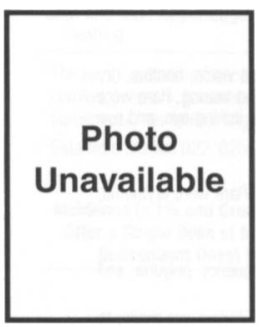

Sarah Kirby

- CNSF Board Member

- NSFC Board Member

- CNS Vice-President

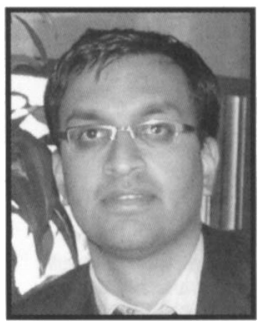

Vijay Ramaswamy

- Residents' Rep. CACN

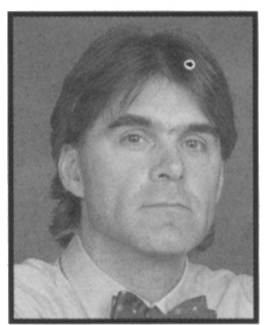

Colin Chalk

- CNSF Professional

Development Committee Chair

- CNS Member

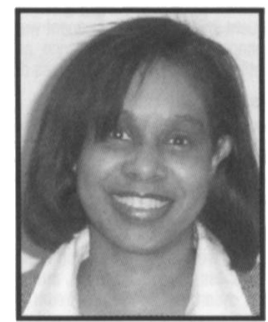

Sharon Whiting

- CNSF Board Member

- NSFC Board Member

- CACN Vice-President

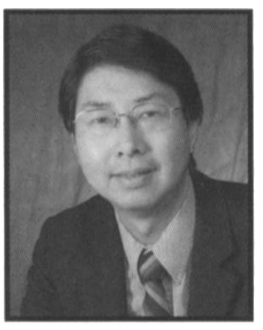

Ming Chan

- CNSF Board Member

- NSFC Board Member

- CSCN President

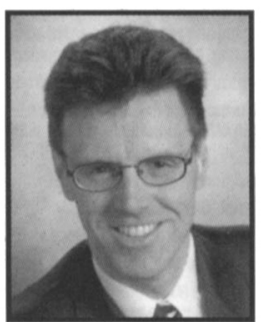

Andrew Kirk

- CNSF/NSFC

Past President

- Non-voting

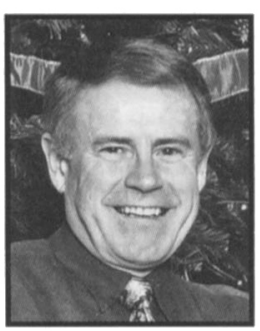

Richard Riopelle - CBANHC Chair

CNSF - Canadian Neurological Sciences Federation; NSFC - Neurological Sciences Foundation of Canada; CNS - Canadian Neurological Society;

CNSS - Canadian Neurosurgical Society; CSCN - Canadian Society of Clinical Neurophysiologists; CACN - Canadian Association of Child Neurology;

CBANHC - Canadian Brain and Nerve Health Coalition 


\section{Annual Congress Registration and Hotel Details}

\section{Full Registration}

- Includes all sessions of the 2010 Annual Congress from Tuesday, June 8, 2010 through Friday, June 11, 2010 and the Exhibitors' Reception on Wednesday June 9, 2010.

\section{One-Day Registration}

- Includes all sessions for the day registered. Note: Wednesday One-Day Registrants can attend the Exhibitors' Reception on June 9, 2010.

\section{How to Register}

- You can register online at www.cnsfederation.org.

- Registration forms are also available in the middle of the Preliminary Program which you will receive in mid-February. You can scan/email, mail or fax to:

Advance Group Conference Management

Suite 101 - 1444 Alberni Street

Vancouver, BC, Canada V6G $2 Z 4$

Fax: (604) 685-3521

Email: cnsfreg@advance-group.com

\section{ACCOMMODATION INFORMATION}

We need your help! Please support the CNSF Congress by booking your accommodations in one of the official Congress hotels, the Quebec Hilton or the Delta Quebec. The CNSF has a block of rooms reserved and has established preferential rates for conference delegates. Both hotels are conveniently located next to the convention centre and feature conference rates that are the lowest you'll find in the vicinity.

If we don't meet the minimum number of delegate reservations, the CNSF Congress will be subject to substantial financial penalties; ultimately these penalties result in a more expensive Congress registration fees in following years. Please show your support and help us by staying at one of our Official hotels! Your loyalty and commitment is appreciated.

\section{BOOKING HOTELS}

- Reservations process: Advance Group accepts hotel requests online at www.cnsfederation.org , in writing via fax (604) 685-3521 or by mail using the CNSF Hotel Reservation Form included in the Preliminary Program. Reservations will not be accepted by telephone.

THIS JUST IN!!!

CNSF 2010 Congress delegates who register and stay at the Quebec City Hilton for a minimum of three consecutive nights during the CNSF Congress June 8th to 11th are eligible for a draw for: a free two nights stay with one buffet breakfast for 2 people and one dinner for 2 people at the Hilton's Allegro restaurant (table d'hôte menus, no alcohol). This prize must be taken between July 1 st 2010 and March 31 st, 2011. This prize is not redeemable for cash.

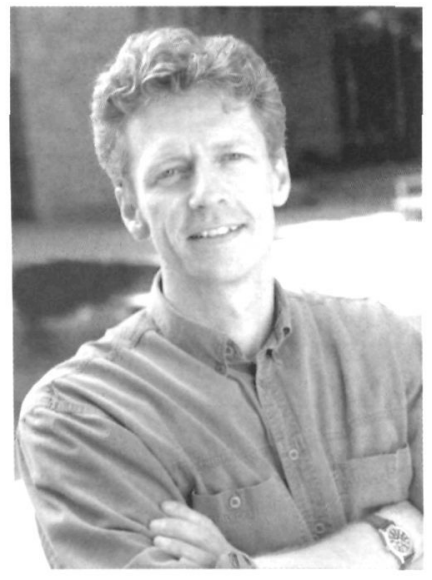

\section{Congress Breaking News!}

Dr. James Orbinski has accepted our invitation to speak as the Distinguished Guest Lecturer at the 2010 Congress of the Canadian Neurological Sciences Federation (June 8 - 11).

Dr. Orbinski is a veteran of many of the world's most disturbing and complex humanitarian emergencies. He accepted the Nobel Peace Prize on behalf of Medecins Sans Frontieres (Doctors Without Borders) in 1999.

A brilliant and mesmerizing orator, Orbinski offers a compelling look at the ravages of genocide and civil war, the role of humanitarianism, and the conflict that arises from combining humanitarian assistance with a political agenda.

Orbinski is an outspoken and passionate speaker who is deeply committed to the core principles of volunteerism and impartiality, with a belief that everyone deserves both medical assistance and the recognition of his or her humanity.assistance and the recognition of his or her humanity. 
NOTES 


\section{EARLy COMMITTED SPONSORS FOR 2OIO}

The Canadian Neurological Sciences Federation is pleased to recognize those Sponsors who have already committed to supporting the 2010 Congress. These organizations partner with CNSF to determine the causes of, and develop treatment for diseases and injuries of the nervous system, and in the care of patients with these diseases and injuries. Along with support of the Canadian Journal of Neurological Sciences and other initiatives the CNSF maintains throughout the year, these organizations graciously provided educational grants to the Annual Congress, this year in Quebec City, Quebec, June 8-11, 2010.

\section{PLATINUM}

MERCK FROSST

Discovering today

for a better tomorrow.

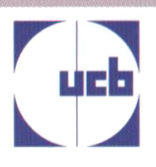

THE EPILEPSYCOMPANY'm

\section{GOLD}
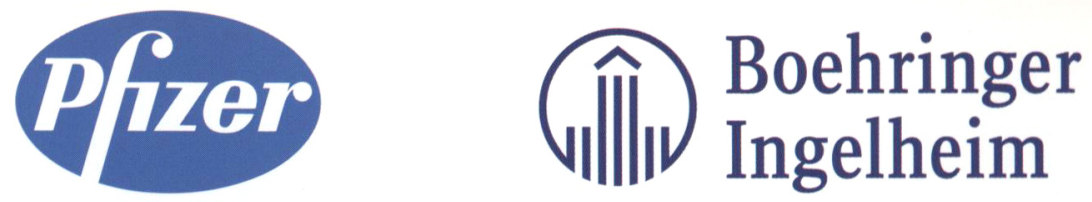

\section{SILVER}

\section{Scotiabank $^{\bullet}$}

\section{BRONZE}

\section{CONGRESS SPONSORSHIP AND EXHIBITOR OPPORTUNITIES}

The Canadian Neurological Sciences Federation's Congress is the largest educational forum and industry show in the country for neurologists, neurosurgeons, child neurologists, neuroradiologists and neurophysiologists. Representing the largest and most diverse neuro-specialist groups in Canada, the Quebec City Congress in June 2010 will again feature exceptionally strong science and hold undeniable corporate value for our industry partners.

If you and your organization would like more information, or would like to discuss how you can partner with CNSF and meaningfully connect with our Congress delegates, please call or email Brett Windle, Corporate Development Coordinator at (403) 229-9544 or brett-windle@cnsfederation.org

Join Canada's pharmaceutical and equipment manufacturing leaders in the neurosciences by showing your support for continuing education and lifelong learning. 


\section{Athena Diagnostics}

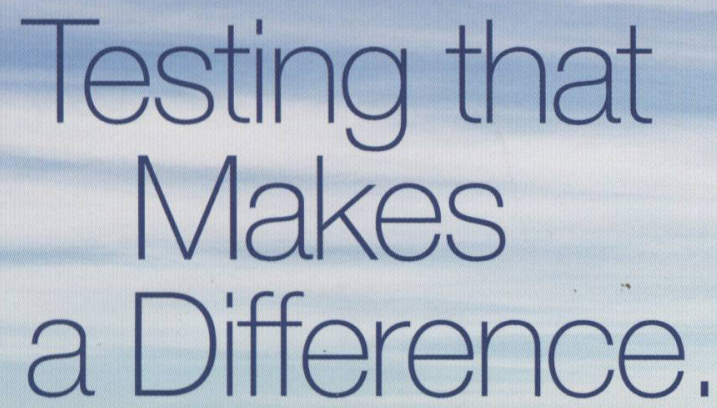

\section{Athena is Your Source for Advanced Neurology Diagnostics}

A Sample of Our Tests Include:

\section{Epilepsy}

- Febrile Seizures Evaluation (\#548) SCN1A, SCN1B, GABRG2

- Complete Tuberous Sclerosis Evaluation (\#556) TSC1, TSC2

Myasthenia Gravis

- AChR/MuSK Reflexive Antibody Test (\#483) Includes MuSK quantitative titers

\section{Peripheral Neuropathy}

- Complete CMT Evaluation (\#404) 15 genes including PMP22, MFN2 and Cx32

\section{Motor Neuron Disease}

- Complete ALS Evaluation (\#723) SOD1, FUS, TARDBP, ANG, FIG4

See our complete menu at www.AthenaDiagnostics.ca

\section{Athena's Tests are EASY to Order!}

- Simple 5-step ordering instructions at www.AthenaDiagnostics.ca

- Athena stores blood samples awaiting Ministry of Health approval so you can order, draw and ship on same visit

- Free FedEx shipping and shipping kits included to reduce send-out costs

For more information, call toll-free (800) 394-4493, Option \#2.

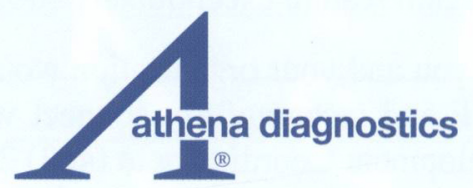

Testing that Makes a Difference. 